\title{
APLICAÇÃO DO PDCA NA OTIMIZAÇÃO DO TRATAMENTO DE EFLUENTE DE LAVAGEM DE EMPILHADEIRAS
}

\author{
G. A. VIEIRA ${ }^{1}$, D. A. SOUZA ${ }^{1}$, I. de S. BARCELOS ${ }^{1}$, O. A. DIAS ${ }^{1}$, T. S. TESSAROLO ${ }^{1}$ \\ ${ }^{1}$ Faculdades Integradas de Aracruz, Curso de Engenharia Química. \\ E-mail para contato: iata@fsjb.edu.br
}

\begin{abstract}
RESUMO - O objetivo deste trabalho foi aplicar o ciclo PDCA na otimização de um processo de tratamento de efluente oleoso, oriundo de lavagem de empilhadeiras de uma empresa do município de Aracruz, norte do ES. As etapas do método incluídas foram planejamento, execução, verificação e ação, 5W2H, diagrama de Ishikawa e o gráfico de Pareto. O tratamento apresentava resultados indesejáveis de sulfetos, óleos e graxas e $\mathrm{pH}$. Uma proposta de melhoria foi elaborada recomendando a utilização do policloreto de alumínio (PAC) como coagulante substituindo o sulfato de alumínio, eliminando o sulfeto do efluente tratado e controlando o $\mathrm{pH}$. Utilizou-se carvão ativado no tratamento, para que a concentração do efluente tratado tivesse resultados de óleos e graxas <20mg/L. Um colorímetro foi adquirido e os operadores da Estação de Efluente Oleoso (ETEO) foram treinados. O PDCA foi um método eficaz na organização do processo de implementação de melhorias, fornecendo um direcionamento de forma objetiva.
\end{abstract}

\section{INTRODUÇÃO}

A poluição pode ser entendida como qualquer modificação das características de um ambiente, de modo a torná-lo impróprio às formas de vida que ele normalmente abriga. Muitas destas modificações têm ocorrido devido à geração de poluentes que estão diretamente relacionados com o aumento da industrialização.

No decorrer das atividades industriais e até mesmo no nosso dia a dia, há uma grande geração de resíduos sólidos e efluentes líquidos ou gasosos, que antes de serem lançados no meio ambiente devem ser tratados para que se enquadrem nos limites de emissão estabelecidos pelos os órgãos ambientais, levando as empresas a buscar soluções para tornar seus processos menos poluentes.

Pode-se tomar como exemplo o efluente proveniente da lavagem automotiva, uma atividade muito comum e, que se não for submetido a sistema de tratamento eficaz pode causar danos a saúde ambiental. Uma característica do efluente citado é a existência de óleos e graxas que, na presença de sabões e detergentes, forma emulsões de óleo em água, que podem ser arrastadas para a estação de tratamento. Os principais poluentes provenientes da lavagem automotiva são os óleos e graxas, particulados e produtos coadjuvantes. Os óleos e graxas são provenientes de combustíveis, lubrificantes e ceras, por exemplo. Ao que se refere aos particulados, tem-se 
sílicas, argilas, poeiras e outros fragmentos que possam permanecer agregados à superfície veicular.

O método de gestão utilizado neste trabalho envolve quatro passos que visam a melhoria contínua de processos e produtos, que é o ciclo PDCA. Método este criado para auxiliar na tomada de decisões e no direcionamento para a resolução de problemas.

\section{MATERIAIS E MÉTODOS}

De acordo com a Resolução CONAMA nº. 430/2011, que dispõe a respeito dos padrões de lançamento de efluentes, estes só podem ser lançados nos corpos receptores após o devido tratamento, a fim de obedecer às condições estabelecidas.

Acompanhou-se resultados de $\mathrm{pH}$, temperatura, sulfetos, óleos e graxas, turbidez, sólidos suspensos totais, sólidos totais e cor, parâmetros de monitoramento adotados pela empresa deste estudo de caso, sob limites definidos na Tabela 1.

Tabela 1 - Parâmetros analisados e respectivos limites

$\begin{array}{cc}\text { Parâmetro } & \text { Limites } \\ \text { pH } & 5-9 \\ \text { Temperatura } & <40{ }^{\circ} \mathrm{C} \\ \text { Sulfeto } & \leq 1 \mathrm{mg} / \mathrm{L} \\ \text { Óleos e graxas } & <20 \mathrm{mg} / \mathrm{L} \\ \text { Turbidez* } & \text { *Sem especificação CONAMA, } \\ \text { Sólidos suspensos totais* } & \text { controle interno } \\ \text { Sólidos totais* } & \\ \text { Cor* } & \end{array}$

Fonte: Resolução CONAMA nº 430/2011.

O tratamento de efluente estudado pertence a uma empresa de lavagem de empilhadeiras localizada no município de Aracruz, norte do estado do Espírito Santo.

Com a finalidade de se obter um planejamento experimental que garantisse o alcance dos objetivos definidos, foi utilizado o ciclo PDCA, cujas etapas e fluxos são apresentadas no Quadro 1 . 


\begin{tabular}{|c|c|c|c|}
\hline PDCA & FLUXO & FASE & OBJETIVO \\
\hline \multirow{4}{*}{$\mathrm{P}$} & 1 & $\begin{array}{l}\text { Identificação do } \\
\text { problema }\end{array}$ & $\begin{array}{l}\text { Definir claramente o problema e } \\
\text { reconhecer sua importância. }\end{array}$ \\
\hline & $\begin{array}{l}\downarrow \\
\downarrow \\
\downarrow\end{array}$ & Observação & $\begin{array}{l}\text { Investigar amplamente o problema } \\
\text { sob vários pontos de vista e avaliar } \\
\text { abrangência. }\end{array}$ \\
\hline & $\begin{array}{l}\downarrow \\
3\end{array}$ & $\begin{array}{l}\text { Análise das causas } \\
\text { do problema }\end{array}$ & Descobrir as causas fundamentais. \\
\hline & $\begin{array}{l}\downarrow \\
4\end{array}$ & Plano de ação & $\begin{array}{l}\text { Criar um plano para eliminar e } \\
\text { bloquear as causas fundamentais. }\end{array}$ \\
\hline $\mathrm{D}$ & $\begin{array}{l}\downarrow \\
5\end{array}$ & Ação & Implementar o plano de ação. \\
\hline \multirow{2}{*}{ C } & $\downarrow$ & Verificação & Verificar se o bloqueio foi efetivo. \\
\hline & & & (O bloqueio foi efetivo?) \\
\hline \multirow{2}{*}{ A } & $\checkmark$ & Padronização & $\begin{array}{l}\text { Prevenir contra o reaparecimento do } \\
\text { problema }\end{array}$ \\
\hline & $\begin{array}{l}\downarrow \\
8\end{array}$ & Conclusão & $\begin{array}{l}\text { Recapitular e registrar a solução para } \\
\text { futuras consultas }\end{array}$ \\
\hline
\end{tabular}

Fonte: Adaptado de CAMPOS (1996).

\section{RESULTADOS}

\section{1. P - Planejamento}

Com base em históricos de monitoramentos do efluente tratado entre o período de abril de 2008 a janeiro de 2013. Os valores do gráfico 1 representam a porcentagem de resultados que estavam fora dos limites permitidos.

Gráfico 1 - Pareto de ocorrências indesejáveis no tratamento

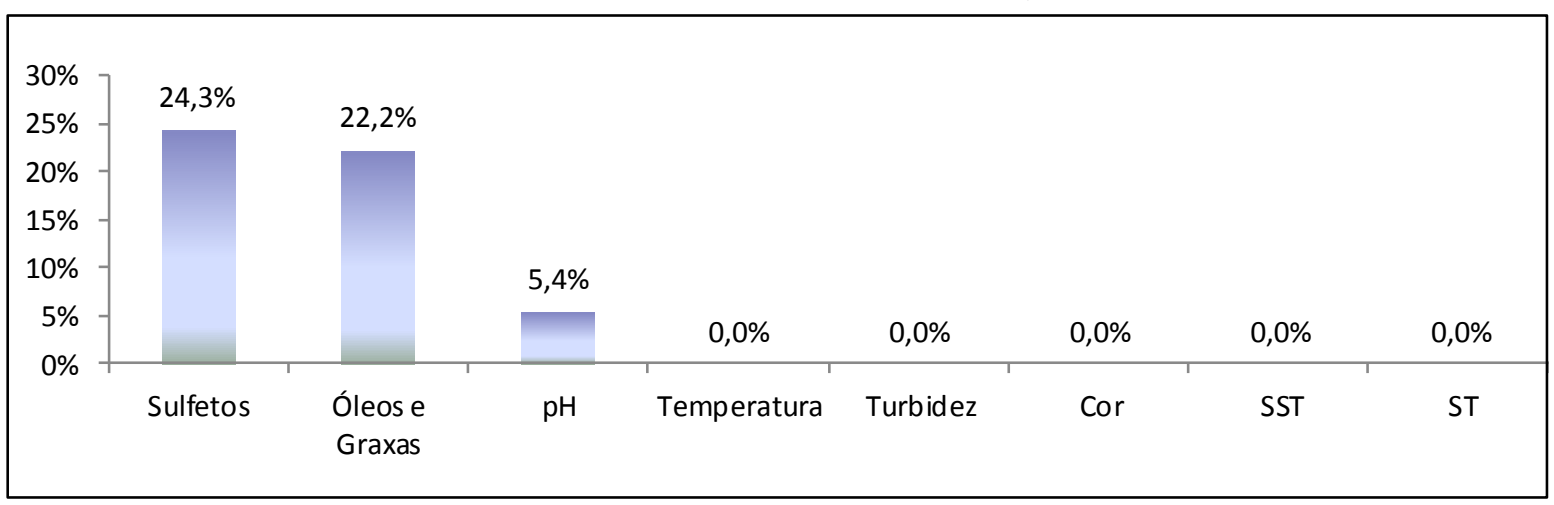


Após análise, definiu-se o problema a ser estudado, onde foi encontrado dois resultados de $\mathrm{pH}$ e oito de sulfetos e óleos e graxas fora do permitido, caracterizando descarte do efluente no mar com parâmetros acima dos limites estabelecidos pela Resolução CONAMA nº. 430/2011.

Durante a etapa de observação, que foi feita na área de tratamento, foi analisada uma tabela de resultados do monitoramento do ano de 2008 (Tabela 2), que foi a única análise de eficiência do tratamento com o sulfato de alumínio, comparando o efluente bruto com o tratado. Mesmo com uma diferença de cinco anos entre o período do estudo de caso e do monitoramento, estes resultados foram utilizados porque se manteve todas as características do processo após março de 2008 até janeiro de 2013, tornando a comparação viável. Esta análise foi importante, pois foi detectado que a concentração de sulfeto aumentava após o tratamento.

Tabela 2 - Concentração de sulfeto no efluente

Data Hora Conc. antes do tratamento (mg/L) Conc. após tratamento (mg/L)

$\begin{array}{cccc}13 / 3 / 08 & 13: 50 & 0,1 & 10,500 \\ 18 / 3 / 08 & 10: 15 & <0,002 & 5,600 \\ 24 / 3 / 08 & 10: 20 & 0,15 & 3,900\end{array}$

Análise das causas do problema: A única etapa de tratamento onde ocorrem mudanças químicas era na adição de sulfato de alumínio, o que indicava que este coagulante poderia não ser o mais indicado para este tratamento. PIVELI, KATO (2006) diz que a redução do sulfato em condições anaeróbicas é realizada por ação biológica, de acordo com a reação apresentada na Equação 1.

$$
\mathrm{SO}_{4}^{-2}+2 \mathrm{C}+2 \mathrm{H}_{2} \mathrm{O} \rightarrow 2 \mathrm{HCO}_{3}^{-1}+\mathrm{H}_{2} \mathrm{~S}
$$

Com a adição do sulfato de alumínio ocorre a diminuição da alcalinidade pela geração de $\mathrm{CO}_{2}$, de acordo com a reação apresentada na Equação 2.

$$
2 \mathrm{Al}_{2}\left(\mathrm{SO}_{4}\right)_{3} \cdot 18 \mathrm{H}_{2} \mathrm{O}+3 \mathrm{Ca}\left(\mathrm{HCO}_{3}\right)_{2} \rightarrow 3 \mathrm{CaSO}_{4}+2 \mathrm{Al}(\mathrm{OH})_{3} \downarrow+6 \mathrm{CO}_{2}
$$

Para corrigir esta diminuição, adiciona-se hidróxido de cálcio $\left(\mathrm{Ca}(\mathrm{OH})_{2}\right)$, que possivelmente nos dois eventos anormais foi adicionado em excesso, gerando $\mathrm{pH}$ maior do que 9. Porém, esta adição em excesso não pode ser comprovada, pois não há registros de dosagem, o que impossibilita a consulta de históricos.

Plano de Ação: Realizou-se uma pesquisa sobre qual o melhor coagulante para substituição do sulfato de alumínio, pois como citado, este gerava sulfeto e diminuía a alcalinidade do efluente. PADILHA et al. (2011), SANTOS (2011) e ALVES; BASTOS; DE MARCHI (2013), por exemplo, destacam a eficiência do policloreto de alumínio (PAC), um polímero sintético, inorgânico, de fácil manuseio, fácil estocagem e dosagem. Reage com as substâncias alcalinas liberando vapores ácidos e 
é bastante corrosivo, atacando metais em geral. Ele substitui com grande desempenho o sulfato de alumínio, consome menos álcalis, pois o $\mathrm{pH}$ do efluente permanece praticamente sem alteração mesmo que dosado em excesso.

De acordo com o responsável técnico do SAAE de Aracruz, onde já foi efetuada a substituição do sulfato de alumínio pelo PAC, o sulfato de alumínio tem um custo médio de R\$ 0,98 enquanto o PAC tem um custo médio de R \$ 1,39. Porém, como a concentração necessária de PAC é menor quando comparada com a de sulfato de alumínio, normalmente tem-se uma economia de $45 \%$ com o uso do PAC.

\subsection{D - Execução}

As ações que necessitavam de um tempo maior para execução eram as análises com o PAC, por isso foram priorizadas. Foram utilizados materiais e equipamentos em parceria com um laboratório de uma empresa do município de Aracruz, o grupo não arcou com nenhum custo.

Para cada teste foram feitas três análises, utilizando um litro de efluente bruto para cada análise, no total de três testes em diferentes datas, conforme plano de ação. Para cada análise foram testadas quatro concentrações diferentes de PAC, 10, 20, 30 e $40 \mathrm{mg} / \mathrm{L}$, afim de avaliar qual seria a melhor concentração para dosagem na ETEO.

\subsection{C - Verificação}

Etapa de verificação da eficácia das ações implementadas, evidenciou-se os resultados dos testes com diferentes dosagens de PAC para cor, turbidez, sólidos suspensos totais e sólidos totais na Tabela 3 e o resultado de $\mathrm{pH}$ na Tabela 4.

Tabela 3 - \% de remoção com diferentes concentrações de PAC

$\begin{array}{ccccc}\text { Parâmetros } & \text { Dosagem PAC }(\mathrm{mg} / \mathrm{L}) & \% \text { - Teste } 1 & \% \text { - Teste } 2 & \% \text { - Teste } 3 \\ & 10 & 54,5 & 44,1 & 23,9 \\ \text { Cor (mg Pt/L) } & 20 & 40,7 & 35,9 & 22,9 \\ & 30 & 39,4 & 37,3 & 28,3 \\ \text { Turbidez (NTU) } & 40 & 44,6 & 43,3 & 40,0 \\ & 10 & 52,3 & 50,5 & 42,7 \\ & 20 & 63,3 & 59,3 & 45,9 \\ \text { SST (mg/L) } & 30 & 73,8 & 63,7 & 45,6 \\ & 40 & 74,3 & 68,3 & 45,4 \\ & 10 & 53,3 & 52,9 & 52,5 \\ \text { ST (mg/L) } & 20 & 29,4 & 54,4 & 52,5 \\ & 30 & 39,0 & 45,0 & 50,0 \\ & 40 & 67,7 & 60,4 & 54,0 \\ & 10 & 18,4 & 35,0 & 11,6 \\ & 20 & 11,7 & 12,1 & 12,5 \\ & 30 & 16,3 & 14,5 & 13,3 \\ & 40 & 8,1 & 10,5 & 13,6\end{array}$


Tabela 4 - Resultados de pH com diferentes concentrações de PAC

$\begin{array}{ccccc}\text { Parâmetros } & \text { Dosagem PAC }(\mathrm{mg} / \mathrm{L}) & \text { Teste } 1 & \text { Teste } 2 & \text { Teste 3 } \\ & 10 & 6,2 & 6,2 & 6,9 \\ \mathrm{pH} & 20 & 6,5 & 6,3 & 6,9 \\ & 30 & 6,4 & 6,3 & 6,8 \\ & 40 & 6,3 & 6,3 & 6,9\end{array}$

Foram realizados dois testes piloto no dia 8/11/2013 nos horários de 9h30min e 11h30min, ambos evidenciados na Tabela 5.

Tabela 5 - Resultados do teste piloto com PAC (10mg/L) na ETEO.

\begin{tabular}{ccccc} 
Parâmetros & Teste & Efluente bruto & Efluente tratado & Remoção (\%) \\
pH & Teste 1 & 7,4 & 7,3 & - \\
& Teste 2 & 7,4 & 7,3 & - \\
Sulfeto (mg/L) & Teste 1 & 0,1 & 3,1 & - \\
& Teste 2 & 0,1 & 0,4 & - \\
Cor (mgPt/L) & Teste 1 & 48,1 & 23,8 & 50,5 \\
& Teste 2 & 81,3 & 25,3 & 68,9 \\
Turbidez (NTU) & Teste 1 & 94,5 & 2,5 & 97,3 \\
& Teste 2 & 313,0 & 29,5 & 90,6 \\
SST (mg/L) & Teste 1 & 160,0 & 4,0 & 97,5 \\
\multirow{2}{*}{ ST (mg/L) } & Teste 2 & 71,0 & 6,0 & 91,6 \\
& Teste 1 & 584,0 & 542,3 & 7,1 \\
Óleos e graxas (mg/L) & Teste 2 & 686,0 & 521,7 & 24,0 \\
& Teste 1 & 339,2 & 4,8 & 98,6 \\
& Teste 2 & 299,8 & 4,1 & 98,6
\end{tabular}

Observa-se que os valores de $\mathrm{pH}$ e as porcentagens de remoção de cor e sólidos totais mantiveram os valores próximos aos obtidos em bancada. Enquanto os valores de remoção para turbidez e sólidos suspensos totais apresentaram melhoria quando comparados com as análises em bancada. A concentração de óleos e graxas após o tratamento manteve-se próxima aos valores do histórico de monitoramento que estavam dentro do limite permitido, contudo não podendo ser comprovada a eliminação de possível reincidência deste problema, mantém-se a necessidade de uma ação preventiva, conforme plano de ação.

\subsection{A - Ação}

A ação de troca do coagulante possibilitou melhoria no tratamento, fato este observado no resultado do teste piloto, já evidenciados na Tabela 5. As concentrações de sulfetos foram 
eliminadas nos ensaios em bancada e à medida que o sulfato foi removido do sistema, as concentrações na ETEO do primeiro para o segundo teste reduziram significativamente, como esperado, de acordo com os testes em bancada. Os resultados de $\mathrm{pH}$ demonstraram estabilidade entre os limites de 5 a 9, característica prevista na literatura com a utilização do PAC. Óleos e graxas apresentaram valores bem abaixo de $20 \mathrm{mg} / \mathrm{L}$, porém foi necessário realizar prevenções para que este parâmetro não volte a apresentar problemas, e que analisando a literatura foi definido que o carvão ativo foi a melhor alternativa, devido a seu baixo custo e por não ser necessário adição de equipamentos e novas etapas no processo.

\section{CONCLUSÕES}

Com base nos resultados obtidos e nos objetivos traçados, pode-se concluir que a utilização do PDCA como método de estudo de caso foi satisfatória. Seguiram-se todas as etapas e aplicaram-se as ferramentas necessárias, direcionando o grupo nas tomadas de decisões, e com auxílio do embasamento teórico da literatura utilizada, os objetivos foram alcançados com somente um ciclo.

Com relação as melhorias propostas, o PAC na concentração de $10 \mathrm{mg} / \mathrm{L}$ já apresentou qualidade no tratamento, atendendo aos parâmetros estabelecidos e ainda gerando benefício econômico, já que não demonstrou diferença significativa nos resultados quando comparados com os demais resultados.

Para o caso dos óleos e graxas, dentre as sugestões apresentadas pela literatura, o carvão ativo é considerado a melhor opção para retenção destas substâncias que interferem no tratamento do efluente, devido sua praticidade, por não alterar o processo e não necessitar da instalação de equipamentos. Devido a forte relação entre óleos e graxas e turbidez, o monitoramento através de um colorímetro será uma opção para dispositivo de controle, onde o operador deverá tomar as medidas para que este parâmetro não venha a ser um item preocupante novamente. Como ações preventivas ficam a conscientização dos operadores da estação sobre a separação manual de óleos e graxas livres e a avaliação do tempo de troca do filtro de areia.

\section{REFERÊNCIAS}

ALVES, V. M. B.; BASTOS, W.; DE MARCHI, U. F. Comparação entre o sulfato de alumínio e policloreto de alumínio em estudo de caso. In: Assembleia Nacional da Associação Nacional dos Serviços Municipais de Saneamento, 43, 2013. Vitória.

CAMPOS, V. F. Gerenciamento pelas diretrizes. 2 ed. Belo Horizonte: QFCO, 1996.

CONSELHO NACIONAL DE MEIO AMBIENTE - CONAMA. 2011. Resolução CONAMA $n^{o}$ 430. Disponível em: <http://www.mma.gov.br/port/conama/ legiabre.cfm?codlegi=646>. Acesso em: 30 mai. 2013. 
SANTOS, G. R. dos. Estudo de clarificação de água de abastecimento público e otimização da estação de tratamento de água. 2011. Dissertação (Mestrado em Tecnologia de Processos Químicos e Bioquímicos) - Universidade Federal do Rio de Janeiro, Rio de Janeiro. Disponível em: http://tpqb.eq.ufrj.br/download/clarificacao -de-agua-de-abastecimento-publico.pdf. Acesso em: 15 nov. 2013.

PADILHA, J. D. et al. Análise da utilização de três diferentes coagulantes na remoção da turbidez de água de manancial de abastecimento. In: Encontro Internacional de Produção Científica, 2011. 7 Maringá. Disponível em: http://www. cesumar.br/prppge/pesquisa/epcc2011/anais/diana_janice_ padilha2.pdf. Acesso em: 15 nov. 2013.

PIVELI, R. P; KATO, M. T. Qualidade das águas e poluição: Aspectos físico-químicos. 1 ed. São Paulo: ABES, 2006. 